Dialectologia 28 (2022), 175-203.

ISSN: 2013-2247

Received 25 February 2020.

Accepted 18 April 2020.

\title{
BUENÍSIMO O MUY BUENO: LA EXPRESIÓN DE LA SUPERLACIÓN EN EL ANDALUZ RURAL CONTEMPORÁNEO ${ }^{1}$
}

\author{
Ana SerRadilla Castaño * \\ Universidad Autónoma de Madrid \\ ana.serradilla@uam.es
}

\section{Resumen}

Este artículo recoge los usos del superlativo sintético -ísimo y de la expresión analítica con muy por parte de hablantes andaluces de áreas rurales a través de los datos recogidos en el Corpus Oral Sonoro del Español Rural (COSER). Se analizan las construcciones en que aparecen ambas formas (como predicado, antepuestos o pospuestos al sustantivo), se da cuenta de la variedad de adjetivos y participios utilizados, se presentan los casos que parecen saltarse las restricciones normativas y, tras la comparación con épocas anteriores, se observa cómo se da una extensión de la forma en -ísimo. Los datos manejados permiten concluir que la forma muy es claramente mayoritaria, pero también que -ísimo, forma culta en un principio, comienza a ocupar un lugar más importante en la lengua de hablantes con un nivel sociolingüístico bajo, que viven en áreas geográficas en las que, según los datos del Atlas Lingüístico de la Península Ibérica (ALPI), era una expresión casi inexistente.

Palabras clave: muy, -ísimo, superlativo, andaluz, español rural

\section{BUENÍSIMO O MUY BUENO: THE EXPRESSION OF SUPERLATION IN CONTEMPORARY RURAL ANDALUSIAN}

\section{Abstract}

This paper collects the uses of the synthetic superlative -isimo and the analytical expression with muy by Andalusian speakers of rural areas, according to data gathered in Corpus Oral Sonoro del Español Rural (COSER). The constructions in which both forms appear are analyzed (as a predicate, pre- 0 postposed to the noun); information is given about the variety of adjectives and participles used; those cases that seem to ignore normative restrictions are studied; and, after comparison with earlier times, an extension of the forms with -ísimo is detected. The data handled lead us to the conclusion that the

\footnotetext{
${ }^{1}$ Este trabajo ha sido realizado en el marco del proyecto PGC2018-095077-B-C42, financiado por el Ministerio de Ciencia, Innovación y Universidades, dirigido por Inés Fernández-Ordóñez y Ana Serradilla Castaño.

* Departamento de Filología Española, Facultad de Filosofía y Letras. Universidad Autónoma de Madrid. C/ Francisco Tomás y Valiente, 1. 28049 Madrid.
} 
form muy is clearly predominant, but also that -ísimo, a cultured Latinism at first, begins to take a more important place in the language of speakers with a low sociolinguistic level, who live in geographical areas in which, according to data from the ALPI, it used to be an almost non-existent expression.

Keywords: muy, -ísimo, superlative, Andalusian, rural Spanish

\section{BUENÍSIMO O MUY BUENO: L’EXPRESSIÓ DE LA SUPERLACIÓ A L'ANDALÚS RURAL CONTEMPORANI Resum}

Aquest article recull els usos del superlatiu sintètic -ísimo i de l'expressió analítica amb muy per part de parlants andalusos d'àrees rurals a través de les dades recollides en el Corpus Oral Sonoro del Español Rural (COSER). S'analitzen les construccions en què apareixen ambdues formes (com a predicat, avantposats o posposats al substantivo), es mostra la varietat d'adjectius i participis utilitzats, es presenten els casos que sembla que vulneren les restriccions normatives i, després de fer la comparació amb èpoques anteriors, s'observa com la forma en -ísimo s'estén. Les dades permeten de concloure que la forma muy és clarament majoritària, però també que -ísimo, forma culta en un principi, comença a ocupar un lloc més important en la llengua de parlants amb un nivell sociolingüístic baix, que viuen en àrees geogràfiques en què, segons els dades del Atlas Lingüístico de la Península lbérica (ALPI), era una expressió gairebé inexistent.

Paraules clau: muy, -ísimo, superlatiu, andalús, espanyol rural

\section{Introducción}

El objetivo de este trabajo es comparar el uso que los hablantes de las áreas rurales de Andalucía hacen de las fórmulas con muy (y su variante $m u$ ) y con -ísimo al expresar el grado máximo del adjetivo. Para ello, me valdré de los datos existentes en el Corpus Oral Sonoro del Español Rural (COSER), tendré en cuenta los datos del Atlas Lingüístico de la Península Ibérica (ALPI) y acudiré a otros corpus que reflejan el habla de épocas anteriores con el fin de observar cómo ha ido evolucionando el uso de ambas expresiones superlativas hasta llegar a su situación actual.

La fórmula elativa más habitual a lo largo de la historia del español es, sin duda, muy + adjetivo. Se trata de una expresión analítica que no presenta ninguna restricción constructiva, ya que el adjetivo muestra una gran libertad posicional que no es tan evidente con el resto de fórmulas superlativas (véase Serradilla 2017) y puede aparecer pospuesto o antepuesto al nombre al que modifica, al tiempo que puede funcionar como predicado. En la época medieval alternaba con much(o), usado sobre todo ante vocal, pero ya en el siglo XIII parece que la antigua distribución mucho, much 
(ante vocal) y muy, muyt (ante consonante) ha quedado superada (como si fuesse obispo o arçobispo o donzella de linage de reyes o de muy alta sangre [General Estoria, v. 1, p. 417]; e lazraron de set mucho fiera cosa en tod essa carrera, segund diz Josefo [General Estoria, v. 2, p. 187]). ${ }^{2}$ La competencia entre ambas formas persiste con fuerza hasta el siglo xv, época en la que muy se erige como claro vencedor; pero aún es posible encontrar algún ejemplo de mucho + adjetivo en el español clásico (que dizque fue cosa / mucho admirable [1529, Ciudad de México: Fragmento de una carta autógrafa de fray Juan de Zumárraga al emperador Carlos $V$, refiriéndole lo sucedido en la ciudad de México durante el viaje de Hernán Cortés a las Higueras]); y todavía hoy en día, esta construcción está viva en algunas áreas rurales de la Península (pero que no venga guerra, que no venga guerra porque, porque es, es mucho mala [Mujer, 86 años, Villel, Teruel]). ${ }^{3}$ No obstante, la fórmula elativa más extendida en toda la geografía del español ha sido siempre muy.

Por lo que respecta a -ísimo, se trata de una fórmula superlativa latina que no llegó, en principio, a las lenguas romances, que lo sustituyeron por expresiones perifrásticas tales como mucho, muy, asaz, harto, bien, fuerte, sobra, tan... en el caso del español; o trés, fort, bien... en el del francés. En la época clásica se reintroduce en italiano, portugués y español por vía culta; anteriormente, en la época medieval los ejemplos son esporádicos y se encuentran sobre todo en textos con un marcado tono latinizante: (del mi fijo duçisimo amas eran sus tias [Berceo, Duelo, 20]; Y pensara que, sin screvirte, mi suavíssima señora, conoscieras de mí la mucha gana que tengo de servirte [1a ed., Salamanca, h. 1495-1497. Luis de Lucena, Repetición de amores]). Buena muestra de este carácter latinizante es que no se usa en la General estoria-obra alfonsí reacia al uso de expresiones con valor formulaico y en la que se hace patente el convencimiento real de que esta lengua romance es lo suficientemente válida como para expresar en ella todo el saber de la época (Serradilla 2018). Tampoco, siglos después, Nebrija hace referencia a esta fórmula y Mena o Santillana solo la usan de forma

\footnotetext{
${ }^{2}$ Los ejemplos del español antiguo y clásico han sido extraídos del CORDE (Corpus Diacrónico del Español), de ADMYTE (Archivo Digital de Manuscritos y Textos Españoles) y del corpus seleccionado por Company para su Sintaxis histórica. Los del español actual pertenecen todos al COSER.

${ }^{3}$ Pato \& Viejo (2016) estudian la distribución de mucho + adjetivo en el español peninsular actual.
} 
esporádica. No será hasta el siglo XVI cuando empecemos a encontrar ejemplos de -ísimo con relativa frecuencia; no obstante, todavía en esta época está muy presente su uso latinizante y se documenta básicamente en un registro culto. Ya en los siglos XVIII y XIX su uso se generaliza y pierde su carácter culto (Wang 2013); no obstante, su extensión no alcanza a la de muy y su presencia en las hablas rurales sigue siendo minoritaria.

Lara (2018), de hecho, afirma, tomando como punto de partida los datos del Atlas lingüístico de la Península Ibérica (ALPI), que -ísimo es una forma prácticamente desconocida en el español occidental en la primera mitad del siglo xx. Como señala este autor: "[...] el cuestionario previó dos oraciones con un superlativo morfológico: la pregunta 277 Una moza guapísima y la 278 Una mazorca grandísima" (Lara 2018: 231). Del análisis de las respuestas obtenidas, Lara concluye que -ísimo es una forma mucho menos frecuente que muy y que su uso se encuentra, en la época analizada, básicamente restringido al oriente peninsular. Para Lara (2018: 236):

[...] la opción sintética (-ísimo) no parecía ser general en el habla vernácula de la primera mitad del siglo pasado. Su extensión se circunscribía al oriente peninsular y alternaba con muy / muito con menor fuerza cuanto más al occidente nos desplacemos.

Una vez trazado este mínimo panorama, veremos a continuación, cómo ha llegado a extenderse su uso en el español rural actual. ${ }^{4}$

En este estudio, como he avanzado, me centraré solo en el uso de muy e -ísimo. Existen, obviamente, otras fórmulas que muestran diferencias diastráticas y diatópicas (bien, harto, asaz, mazo, tope, fleje, super-, mega-...), y que quedarán fuera de este artículo; de ellas ya me ocupé en otro trabajo reciente (Serradilla 2016), por lo que no volveré a tratarlas en las siguientes páginas.

\footnotetext{
${ }^{4}$ Para profundizar en la evolución del superlativo sintético véanse Serradilla $(2005,2008,2017$ y en prensa) o Zielinsky (2013).
} 


\section{Análisis del corpus}

\section{$2.1 \mathrm{El}$ uso de muy}

He localizado en las ocho provincias andaluzas un total de 1141 casos de muy + $\operatorname{adjetivo~}^{5}$ y el número total de adjetivos que aparecen graduados por muy en el área analizada es de 224 , cifra muy superior a la que después veremos en el caso del superlativo sintético. En principio, en el COSER se localiza un número mayor de ejemplos de muy en esta área lingüística, pero he restringido mi campo de estudio a los casos en los que esta forma acompaña a un adjetivo, por lo que he eliminado todos aquellos en los que acompaña a un adverbio (muy bien, muy mal, muy tarde, muy pronto...). ${ }^{6}$ Asimismo, solo he tenido en cuenta aquellos casos que aparecen utilizados por los informantes.

El adjetivo que más veces aparece modificado por muy es bueno (180 apariciones), seguido de malo (101), bonito (98) y grande (83). Excepto bonito, que no es usado por los informantes de Granada del corpus, los demás se documentan en todas las provincias andaluzas. Como puede observarse, estamos ante adjetivos patrimoniales de alta frecuencia de uso en español. Entre el resto de adjetivos, los hay con una frecuencia relativamente alta como poco/a/os/as (50 casos), joven (24), rico (22), duro (20) o chico (17), mientras que hay un buen número de adjetivos que solo documentamos en una ocasión: cachondo, endeble, apretao, elegante, envidioso, alegre, cateto, estirado, exagerao, abnegado, molesto, corpulento, costoso, noble, vivo, hermoso, patán... Propongo una mínima muestra de estos últimos:

\footnotetext{
${ }^{5}$ La distribución por provincias es la siguiente: Málaga 344 , Almería 81 , Granada 138 , Jaén 56 , Sevilla 122, Córdoba 149, Cádiz 108 y Huelva 143. Dado que el número de palabras en cada provincia es diferente, no es posible llegar a conclusiones fiables en torno a en qué área se usa más esta construcción. En todo caso, observamos 619 casos en Andalucía Oriental frente a 522 en Andalucía Occidental.

${ }^{6}$ También he eliminado del cómputo casos en los que modifica a un sintagma preposicional: muy de ellos, muy de gala, muy de entendío, muy al día o a la locución a gusto. Del mismo modo, no he tenido en cuenta un caso en el que modifica a todo: "Pero a lo mejó otro hubiera tenío otra cosa, porque es mu bueno y mu lindo y mu $t(o=$ odo ), pero es más serio. Ya habla más, pero antes ha sío mu serio" (Alanís, Sevilla).
} 
1. Me acuerdo todo eso de la comunión, y de mi vestío, que era mu feo [HS:E1 [RISA]]. Unos bullones por aquí porque, mi madre le dijo, porque ellas eran unas costuras mu buena: «Bueno, ia vuestro gusto, a vuestro gusto!». Y, y tenía así uno | muchos bullones y por abajo tres bullones, la tela asín rizá,] vaya yo aquel día iba loca de contenta con él, pero luego después cuando me veo en los retratos y veo mis amigas y digo: «Uy, mamá, el vestío mío era mu cateto». (Antequera, Málaga).

2. Siempre está encima [A-PIn: de] mí, poque yo soy muy [A-PIn: patán], ¿sabes? Me dice: "Toma, ahí va esto, esto, esto, esto». Vaya, que yo estoy contento con la mujé. Poque d' aquí [CARRASP] aquí personas, $\mathrm{m}$ 'han dicho que si no quiero está con esa me voy, con ella | con otra, pero digo: «No yo ya me quedo con esta mujé». (Casariche, Sevilla).

3. Dicen que es mu fantasioso, peo si el hombre tiene dinero, si el hombre va a pagá y siempre tiene unos pocos de billetes, y él no los ha robao, dice: "Si yo lo he ganao». En los barcos, en trapicheá cosas, que sabe Dios lo que habrá trapicheao también. Pero... también lo critican la gente porque... Pos no hubiera hecho ese na en el pueblo, imadre mía! (Jubrique, Málaga).

4. Antes no iban los hombres a misa, hija. [HS:E1 Aquí no.] Eso aquí, no. Como no fuera una misa de alguien que... de una misa de difuntos, o una misa de... de algún entierro, o, o del año o eso... No, porque aquí era el, el campo, es mu campurro, y esos no iban a misa. [HS:E [Asent].] Se casaban, el que se casaba por la iglesia, y... y si había algún bautizo, y ya está. (Jubrique, Málaga).

5. El chico siempre está con mi madre diciéndole cosas, dice: «Te voy a dá un paseo en la silla de ruedas, te voy a llevá al parque». El otro [OTRAS-EM] es de más capacidá, claro, tiene treinta años y el chico tiene veinticinco; son cinco años de diferencia, quieras que no y... Según la condición de lo..., la gente, porque a lo mejó son de ochenta años y son mu chuflones y..., y con mucha gana de guasa siempre; y otros más jóvenes no tienen tanta gana de..., (Villablanca, Huelva).

También hay casos en los que aparece el adverbio muy pero se omite el adjetivo al que debería modificar (56 ejemplos); estamos ante una sintaxis truncada propia de la oralidad. Lo que ahora propongo es una breve muestra de esta última construcción; a los diversos adjetivos me iré refiriendo a lo largo del trabajo:

6. Aguantar, yo no, mi marío no ha sío mu... pero de más mayor como los de la edá de mi madre y eso, esas han pasao... (Jubrique, Málaga).

7. y así, esa era nuestra vida... Una vida..., pues eso, ahora eso sí, muy sana, muy..., gente muy... | que no es como hoy, no... | por lo menos hoy es que se oye cada cosa que, que, que... Ay (é = er) o antes de ayé que entraron con una pistola en ro- | en, en la carona | en el banco, y se lle- | con la pistola en la mano y se llevaron, aquí en el pueblo y se llevaron el dinero y, y..., y, y tantísimas cosas como se ven de los chavales, las drogas, lo otro, en aquel entonces no existía eso, eso no... Era una, una, una vida que era [OTRAS-EM] digamos, mala, porque mala porque había necesidá , pero que era muy..., no sé, yo recuerdo aquella vida..., ojalá hoy estuviera la gente como..., como en aquel tiempo, (Aguilar de la Frontera, Córdoba). 
8. O sea pues yo la niñez pues sí; que luego venía, pues jugaba pues yo que sé, a escondite, o, yo que sé, a saltá, al salto la muerte que decíamos salto de la muerte que uno se agacha y otro salta por encima. [HS:E1 ¡Ah! [Asent].] [HS:E2 [Asent].] Bueno. Yo que sé a lo mejor aquí en la plaza, a lo mejó porque te daban ca guantazo en la oreja, en la cabeza [RISAS] que se ponía mu, mu, pum] y leñazo y te daban. A, aquí a lo moro, como yo digo, [HS:E1 [RISA] a lo bruto, pero bueno. (La Calahorra, Granada).

9. Sí. No como ahora, que ahora cada uno tiene su cama. En colchones, en sacos de paja dormíamos. Así poníamos a lo mejor las chiquillas toas juntas, a los muchachos juntas, los matrimonios en otro lao y, y así estábamos tos. Allí con | bueno, estábamos tos revueltos. Juntos pero revueltos, pero no juntos. [HS:E Ya, ya, ya.] Pero que aquello era mu, mire usted, no es como ahora, ni que había tanta maldad. Aquello era mu bonico, mu bonico de verdad. (Los Pascuales (La Puerta de Segura), Jaén).

Por otro lado, en lo que respecta a la posición de los adjetivos, en el habla coloquial es difícil encontrar casos de anteposición del adjetivo graduado; así, en el COSER se observan solo 43 ejemplos, que suponen el 3,77 \% de los ejemplos documentados; además, hemos de tener en cuenta que en muchos de ellos se trata del cuantificador poco (22 ejemplos). Quitando este, hay que destacar que solo hay dos adjetivos que parecen admitir esta posición en la documentación extraída del COSER: bueno (15 casos) y malo (6 casos). Propongo una pequeña muestra:

10. Mira, niño, se lo voy a decí a tu padre!", digo. "¡Y se lo voy a decí yo antes que tú! ¡Y me voy a cagá en la leche que te..., te..., de que te..., te...!". Y te dicen más que lo que hay en el libro, ¿ieh? Hoy hay mu poca vergüenza en muchos, claro; vergüenza siempre habrá en la vida, sí. (Álora, Málaga).

11. I1: No... a mí me gustaba está en Sevilla. [HS:E2 ¿En Sevilla?] Sí, yo me vine de muy mala gana. [RISAS] Lo que pasa que él... Pero mira, tenía un trabajo, era soldador, estaba en El Cano, era soldador de barco, porque ahí hay un río, que está el río Genil y él se junta con el otro, con otro río, no me acuerdo ahora mismo. (La Atalaya (Villanueva de Algaidas) Málaga).

12. Él decía que le gustaba el campo, que a mí no me había ido tan mal en el campo y, itotá!, y en el campo está, [HS:E1 [Asent].] pero que..., ihombre! yo soy un enamorao de los jóvenes porque los jóvenes tienen una preparación muy buena, tienen muy buena preparación, y el joven que es bueno, los hay como, como lo-, los habría antes también, ipor supuesto! (Aguilar de la Frontera, Córdoba).

13. 11: ¡Ah! Ahí había un rincón mu grande. muy buena lumbre da. (Los Tablones (Órgiva), Granada). 
14. Romances cantan pero yo pa eso tengo mu mala memoria, yo oigo una cosa ahora y al ratillo ya no m'acuerdo. (Constantina, Sevilla).

15. Usté..., mi madre... Vi a empezá con mi madre. Mi madre le arreglamos nosotros lo de la ley de independencia... y nos aprobaron al año o por ahí. En esas fechas se cogía mu buen dinero. De que me lo empezaron a arreglá hasta que nos..., nos lo dieron, todos esos meses nos lo cubrió, y cogimos una buena cantidá de dinero. (Villablanca, Huelva).

16. El chorizo no es cocido, el chorizo se le echa, [OTRAS-EM], mucha carne con muy poca pringue, para que no tenga mucha pringue y se le echa pimiento molido, ajo, [OTRAS-EM], pimienta para que pique un poquito, el pimiento molido también que pique un poco y se hace, mucha gente le echa un poquito de vino. (Espera, Cádiz).

17. Primero se echa la, una calderá con | la echamos, por lo menos nosotros, una calderá con la güeña, porque la güeña es menos, que sale mu poca cantidad y se hace con to lo que se, se le quita al corazón así del, de, de to. To lo que va de sangre de la carne to con eso lo hacemos la güeña, ¿sabe usted? (Los Pascuales (La Puerta de Segura), Jaén).

La posposición es, sin embargo, más abundante. He documentado en el COSER un total de 297 casos de adjetivos pospuestos (26,03\%). Obsérvese que en todos ellos (salvo el ejemplo 28) el nombre al que acompaña el adjetivo modificado por muy está precedido por un artículo indefinido:

18. Yo he hecho muchísimo queso, yo, yo, yo, yo... Pero ya mayó, ya mayorcito, [OTRAS-EM] con veintidós años o por ahí tenía yo una..., una piara, se dice una piara, un rebaño de..., de cabras. Y había trescientas y pico, y, y yo hacía quesos en el cortijo. Había unos..., tenía unos bidones mu altos así, bidones, y los llenamos de..., de leche. (Álora, Málaga).

19. Te tienes que llevá llevar un avareaó que te cuesta unos cicuenta o sesenta euros, y... y, y, y por lo menos dos mujeres tiene que habé haber arrecogiendo los toldos y, y... Y eso era una I T'has, t'has dao la vuelta ya y no tienes | Bue-, tan solo tenemos un olivarito mu bueno también, y dice mi Anto-, mi hijo: "Mamá, ya no se cogen más aceitunas". (Jubrique, Málaga).

20. 12: No, no, de vestida no. Es de I ¿cómo le voy a decir? Una imagen de como si digamos de, de tiesto, pero de lo que hagan eso. Una virgen mu bonica con su niño. (Los Pascuales (La Puerta de Segura), Jaén).

21. El más chico, mi [NP] pues tenía ya, ya... cerca dos años y le dio una tosferina mu mala, mu mala. Y no contaban los médicos con él. (Aulago (Gérgal), Almería).

22. Y entonces había un pasillo muy largo cuando ya salí a la, a la calle. Así puesto, había una baranda y la gente que había esperándolo a un lao y a otro. Y yo [A-PIn: na más] que andando con mi maleta y mi bolso, cuando entonces mi marido salió así por debajo [A-PIn: me echó los brazos por aquí] y yo ya vi el cielo abierto. (Bacares, Almería). 
23. Eso en mi casa no se vía, [R-Vhc] porque llegaba mi abuela y parece que llegaba a mi casa el ministro. [EXCL] Nos la comíamos a besos, y un respeto mu grande, en mi casa había mucho respeto, con mi gente, ojú, con mis tíos, con mis tías, (Torrecera (Jerez de la Frontera), Cádiz).

24. 12: Había una diferencia muy grande porque yo... | de ellos..., y me meto yo también, porque... al no tener posibilidades de estudiar nada a que tus hijos..., tú les pagues la carrera, cuando antes tú con siete u ocho años ya tenías que empezar a trabajar. Fue un, un salto enorme. (San José de Malcocinado (Medina-Sidonia), Cádiz). ${ }^{7}$

25. Y entoces, esa es mi iglesia, ¿sabes?, esa es mi iglesia, ese médico sin fronteras, esa moja que pueda está allí, esa enfermera, ¿tamos? Y esa es mi iglesia, esa es la que yo quiero. [Asent]. Pero luego... esto [OTRAS-EM] [HS:E [RISAS]], una barriga muy gorda..., [RISAS] mucho... tonterías , y, y además eso, ¿no? Yo de verdá eso ya, ya me hace lo contrario, (Chucena, Huelva).

26. Hombre allí si te quieres bañá te puedes bañá pero es un charco que está hecho un risco y tiene un sitio mu raro pa entrá. Mira a mí me falta en ese un deo y aquí me falta otro cacho. Este se partió... Ahí pa entrar en el charco tiene que darte poco miedo porque hay que subir unos riscos pa ir a é. (Cortelazor, Huelva).

27. Y dice: «No, es una paletica mu mu mu... un jamoncito mu regulá», poque hay la paletilla, que la paletilla tiene más huesos que jamón, [HS:E [Asent].] porque el jamón tiene más magro. $Y$ te cunde más el jamón que la paletilla. (Almadén de la Plata, Sevilla).

28. era el tiempo de minifalda, de las minifalditas. Yo estaba asín , delg ( aí = adi ) ta, delgaíta del to. Ves cómo estoy, pos estoy gorda. <risađ< span="">]</risađ<> [RISA]. [HS:I1: [RISAS].] Finita, asín como ella, mu finita. Con la faldita muy cortita, mu estrechita, azul marino y ahora una chaquetita entallaíta, con unos..., un escotito asín ... Y aquí llevaba, del ramito de azahá, porque antes no podían llevá los ramitos de azahá na más que la que iba pura. <asentđ< span="">iAh!] $<$ /asentđ<> [Asent]. (Alanís, Sevilla).

29. Pos que $m$ 'han contao que se llamaba don Fadrique y empezó a hacer una casa, que hay una casa allí riba que tiene un balcón mu antiguo que le dicen la Casa los Patiños, que la hizo aquel. Y empezó pos Puebla de Don Fadrique, porque era él Fadrique (Puebla de Don Fadrique, Granada).

30. Estas están acostumbrás, igual que mis nietas, mis nietas... ivaya! [V-Ljn] [A-Inn] Yo es que no, no, no... | que no me ha gustao... nunca el..., el horno..., de la hornilla... sí, porque tiene un horno muy hermoso. [HS: 12 Bueno...] iHala! [NP] gracias. Adiós. (Los Tablones (Órgiva), Granada).

31. hay muchísimos, muchísimos animales de monte, y... si es lo que es la parte agrícola, de Andalucía pues... es una parte muy rica, una... Yo diría que es de lo más rico de España porque yo

${ }^{7}$ Con este adjetivo se documenta también un ejemplo en una construcción negativa: "Y entonces el hijo que se castaba se quedaba y el otro salía, ¿sabes?, porque es que era un campo no mu grande, era pa ir los..., vamos, [OTRAS-EM] pa llevá..., está allí con sus padres y tus..., sus padres te daban... <asentđ< span="">]</asentđ<> [Asent]. ¡Ah!, ¿tú no sabes cuánto nos daban por estar en el campo?" (Alanís, Sevilla). Es el único ejemplo de este tipo localizado en el COSER. 
he viajado mucho, ya digo, ihombre!, he viajado mucho no, pero que... Barcelona, lo que es toda Cataluña, y... eso, Ávila, Burgos, y... Cantabria..., Asturias y todo eso (Aguilar de la Frontera, Córdoba).

32. Yo tuve que [A-Inn] malo con la crisis, el que viene es peó. Porque si hubiera aceituna, pues la gente coge un dinerito mu apañao, lo administraba lo mejó que pudieran, ¿no? Y comerían, pero munchos... están comiendo los niños en ca los abuelos, el otro en ca el hermano. (Cañete de las Torres, Córdoba).

En todo caso, la construcción más habitual con diferencia es aquella en la que el adjetivo graduado por muy funciona como predicado $(70,2 \%)$. Lo más frecuente es que funcione como atributo de un verbo copulativo pero también aparece como predicado de otros verbos:

33. Y el trigo en el verano estaba mu fresquito, estaba suelto; [A-PIn: coño], nos íbamos al atroje a jugá, a jugar nosotros y casi siempre salíamos... (Álora, Málaga).

34. ¿Qué queréis que sos diga? Pero aluego me encuentro muy sola, se murió mi marido... [HS:E1 Ya.] y muy sola, yo no soy, yo no tengo ganas de... de ir a Juan y Medio a buscar novio, está ese pograma... ¿Lo veis? (La Atalaya (Villanueva de Algaidas), Málaga).

35. Sí, sí, sí te ponías mu malo pos venía a tu casa [HS:E2 [Asent].] y si no pos..., porque este, este consultorio no l'había, [TOS] no l'había, no. (Santaella, Córdoba).

36. iExactamente! Pegada al ambulatorio de la, de las medicinas iExacto! Es donde está actualmente la... plaza de abastos, es muy pequeña ya en comparación a la que había antes. Pues ya digo antes era una... | ienorme! Antes había muchísimos puestos, o paradas, como le llaman, y había muchos, muchos. Y de ahí es donde, podíamos... (Aguilar de la Frontera, Córdoba).

37. Sí, sí. Es una manecilla que lleva cuatro o cinco dientes o seis o siete dientes y es mu cortilla, es pequeña así. Y eso, y eso coge la rama y tira y cae al fardo, cae al fardo del suelo y cae, sí. Sí. (La Calahorra, Granada).

38. Hombre cuando se ponía uno siempre se llevaba uno la escopeta por si eso, pero esos eran mu astutos, eh, esos les daba el tufo y no llegaba, eh. [HS:E1 [Asent].] Esos se las sabían toas. (Constantina, Sevilla).

39. El blanco lleva el..., la carne magra solamente, un poquino de grasa, porque, si no, se pone mu seca, la pimienta y el clavo. Ahí viene alguien, no sé si es mi hija. (Villablanca, Huelva).

40. Se casó con uno de Sevilla, y está en un bar. Mis hijos también. El bar lo pusimos mi marido y yo, donde vivó | donde vivimos nosotros [R-Ind]; allí en | y al morirse mi marido pues ya mis hijos lo reco- | cogieron el ba, porque yo ya estaba mu cansá. Veinticinco años me he llevao en el ba, ¿eh? (Zufre, Huelva). 
41. Lo que pasa que voy a salir mu, mu fea. (Algar, Cádiz).

42. Bueno, pues nosotros teníamos a lo mejón diez sacos de garbanzos y llegaba la Fiscalía y decía que no, que decía mi abuelo: «Si eso lo tengo yo pa mí. Yo lo tengo porque, a lo mejón, pasa un hombre, y yo le pongo un potaje de garbanzos y le saco». "Ustedes son muy generosos», y nos quitaban los garbanzos y se los llevaban, los confiscaban, que tú no podías tené; y el pan, eso era una cosa mala. (Espera, Cádiz).

43. El grande na más, no. Y mi | es mu esclavo eso y mu sucio y muy expuesto, más de lo que se cree la... Los, los dedos mira, cicatrices, [G-Mst] ¿las ves ? (Terque, Almería).

44. Después en las eras, que to eso desapareció, la era era una cosa circunferencial que se tenía muy dura, y allí vaciaban, vaciaban la mies, a los cereales una vez eso se les llamaba mies. Las mieses. (Arjona, Jaén).

45. Sí, ya estaba casá, yo no, no como mis yernos, que se pusieron novios y al otro día ya estaban tos en mi casa. [RISAS]. Yo tam- | Yo ya le digo que ya me he puesto mu moderna [RISAS], poque como ya he pasao to. (Los Pascuales (La Puerta de Segura), Jaén).

Se han podido documentar tanto adjetivos propiamente dichos como participios verbales modificados por muy. De estos últimos encontramos una buena cantidad en el COSER: apañado, apretao, retirao, adornado, disgustá, rescatao, desmayao, vigilao, animado, joío, tapá, preparado, aburrido, raído, arrepentido, mimado, estirado, exagerao, vestido, apurá, renovado, abnegado, necesitado, consentío, arreglao, distinguido, acostumbrado, atrasao, helá, relajao, educado, correcto, desordenado, apegado, divertido, cogido, cansado, sufrío, pesao, picaíto, cerrado, estripao, batío, achuchá, abierta, agradecido, sacrificao, corrupto, amparao, poseído, molía, enamorado, aseá, sentía, espabilá, partío, parao, mondaíto, sujeto, expuesto, retirao, atao, adornao, aficionado o desconfiá.

Bosque (2015: 171) señala una peculiaridad en el caso de que muy modifique a participios:

Cuando el adverbio muy modifica a los adjetivos y participios perfectivos (lleno, quemado) denota un estadio avanzado en el proceso significado por el verbo. Sin embargo, usado con los participios de verbos no perfectivos, adquiere un significado iterativo, concretamente relativo al número de veces que la acción se lleva a cabo o al de personas que la realizan. La gramática no debe explicar 
únicamente el significado de sintagmas como muy lleno o muy cocido. Debe prever hechos tan simples, aparentemente, como que el SN un museo muy visitado no significará 'un museo visitado con intensidad' o '... durante mucho tiempo' [...]. Por el contrario, con un hombre muy enfermo no designamos un hombre propenso a caer en la cama cada dos por tres. En Bosque (1990) se sugiere que el valor gradativo que se atribuye a muy es una noción imprecisa, ya que unas veces alude a marcas perfectivas que los adjetivos contienen léxicamente en su estructura argumental, mientras que otras representan un cuantificador distributivo sobre individuos o sobre puntos temporales, si se trata de predicados verbales no perfectivos.

Este hecho es el que permite explicar los distintos valores que podemos adjudicar a los participios modificados por muy que aparecen en el COSER: así, la secuencia muy + participio formada por participios tales como apretao, retirao, adornado, disgustá, rescatao, desmayao, vigilao, animado, joío, tapá, preparado, aburrido, raído, arrepentido, mimado, exagerao, apurá, renovado, necesitado, consentío, arreglao, distinguido, acostumbrado, atrasao, cogido, cansado, sufrío, pesao, vestido, cerrado, estripao, abierta, entremetío, agradecido, sacrificao, corrupto, amparao, poseído, enamorado, aseá, sentía, espabilá, partío, parao, sujeto, expuesto, retirao, atao, adornao, aficionado... se interpreta como indicadora de un estadio avanzado (ya que estos participios entrarían en el grupo de adjetivos/participios con carácter esencial); mientras que en el caso de molía, picaíto, batío o mondaíto, lo que podría interpretarse es que estamos ante una acción que se repite. Estos últimos casos, efectivamente, se podrían considerar frecuentativos; proceden de verbos de acción que entran en la esfera de lo resultativo y es interesante ver también cómo aparecen en un universo discursivo que trae consigo esa idea de frecuencia característica del tipo de texto instructivo (recetas) en que se usan. Véanse algunos ejemplos de ambos tipos de participio:

46. Después, como también habían tantos lutos, porque unos porque la guerra y a otros porque los mataban, pues había mucha tristeza, las mujeres estaban mu vestías de negro, de eso sí me acuerdo yo. (Antequera, Málaga). ${ }^{8}$

\footnotetext{
${ }^{8}$ Obsérvese que, en principio, el uso relacional del participio impediría en este caso la gradación. Sobre este punto volveré más adelante.
} 
47. Mi madre, sí. Mi madre pa él, sí. Eso sí. Era una persona... | Nunca nos faltó co-, de comé... eso sí que... y en mi casa to el que llegaba comía, ¿sabes? Había personas muy necesitás... y..., y, y llegaba | venía un hombre pidiendo que era de Moriles (Aguilar de la Frontera, Córdoba).

48. Pues que están mu consentíos... " No quiero comé comer esto, no quiero comé comer lo otro", no pasa... Y... y eso to, to, to. Los niños hacen lo que quieren. Le dices: "Que vengas antes de las doce", viene cuando le sale su alma, ¿sabe? (Cañete de las Torres, Córdoba).

49. [HS:I3 Poco se lleva.] [OTRAS-EM] Poco se lleva. [HS:E2 Poco se lleva.] Sí... Son muy relajaos la gente de Graná. (Los Tablones (Órgiva), Granada).

50. que no me ha llamao siempre mu cogido a... a las madres, ¿sabes? [A-Inn] Que si muchas veces las madres que si te echabas cualquier, dice: "Oye esto te interesa». En fin, las madres siempre estaban antiguamente encima de los hijos, encima de los hijos estaban (Casariche, Sevilla).

51. Mi padre se dedicaba... a sembrá en el campo. [HS:E A sembrar en el campo.] Tenía una finca arrendá [HS:E [Asent].] y estaba mu adicto en el campo, con las cabras, los guarros... Mis hermanos se iban con los cochinos, otro con las cabras, después entró la guerra, y se los llevaron a..., a eso, a... a... a la guerra luego a los dos; y, y estábamos solos, [A-Inn] mi padre uno [HS:E3 Te coloco,] (Almadén de la Plata, Sevilla).

52. Es así, pues ahora por aquí tiene una-, unas venas que le salen pa acá [G-Mst] [HS:E [Asent].], y otras aquí junto al hueso, un hueso que tiene | a mitad de jamón va un hueso grande y luego tá por aquí [G-Mst], pues ahora coges tú, y haces así: [G-Imt] lo estripas , lo estripas , mu estripao , y sale la sangre. Primeramente busca esta vena, esta vena, y luego busca esta de aquí, y lo desangre, cuando ya está desangrao, lo dejas colgao, esta noche, toa la noche ahí colgao. (Almadén de la Plata, Sevilla).

53. Sí, esto era del campo todo, todo del campo. Lo que pasa es que ahora está mu parao porque claro... no se puede trabajá el campo que no hay tampoc- | y ahora con las máquinas..., las máquinas hacen las veces de las personas. (Zufre, Huelva).

54. Normalmente... no lo sé, es un trabajo bastante malo, es muy sacrificao. Y... posiblemente porque le paguen menos. (Chucena, Huelva).

55. Vestías de pastoras, una falda, un pañuelo muy atao en la cabeza como, las pastoras [RISA] y ellos igual, los muchachos pos lo mismo. (Bacares, Almería). ${ }^{9}$

56. Hombre, sabemos lo que le decíamos las cuatro reglas: sumar, restar, multiplicar y dividir. Leer, lo corriente, yo he sío siempre muy aficionao a leer, eso sí. Es lo que más me ha gustao leer. Por lo demás, pues... [A-Crt] (Arjona, Jaén).

57. Se pone la olla exprés, le das su vuelta , y la..., y la pones, y a los tres cuartos de hora la aparto yo, y entonces tengo picá la berza, si es durita, la berza, le doy un hervor bueno antes en

\footnotetext{
${ }^{9}$ Aquí el participio no implica que 'se haya atado mucho' sino que se ha atado 'con mucha fuerza'.
} 
otra olla, si yo veo que está tiernecita, [A-Inn] y está tiernecita como la tagarnina, que se coge en su tiempo y está tierna, el cardillito que está tierno, pos eso yo lo enjuago, lo pelo mu mondaíto, mu mondaíto y lo echo, y le majo dos o tres pimientos secos, de eso que le llaman añoras. (Torrecera (Jerez de la Frontera), Cádiz).

58. Las tortás, tal de... | se echa la manteca [R-Vhc], un kilo de manteca, y coges dos kilos de harina y, y le echas lo que admite luego, eso lo bates tú mu batío, le echas el limón en otro lao, [R-Ind] y punto, o sea... Y, y esto, y aceite. Un poquito de aceite también pa que se pongan... |a mí me gusta más, con un poquito de aceite que sola con manteca. Y a-, y su... clavo (Almadén de la Plata, Sevilla).

En todo caso, ha de tenerse en cuenta que muchos de los participios aquí mencionados parecen haber perdido su carácter verbal para convertirse en auténticos adjetivos y, así, lo recoge, incluso, en la mayor parte de los casos, el DLE:

59. Luego, pa venime yo, tuve yo que tener a otra muchacha pa enseñala. La mujer no quería que me viniera. Y, y se ponía, decía la mami: «Prohíbele muchas cosas». Claro, aquella era mu espabilá. Decía, me decía a mí: «Esta lo que teme que enamore yo a su hijo». Digo: «Ya vamos buenas, una huyendo y otras, y otras queremos». (Los Pascuales (La Puerta de Segura), Jaén).

60. tenéis, tenéis..., valéis toas mucho. De verdad que no habéis ninguna saboría saborida ni na. $<$ risasđ $<$ span=" "> $<</$ risasđ $<>$ [RISAS] <risasđ $<$ span="" $>$ ] $</$ risasđ $<>$ [RISAS]. Mu sonri ( $y=0$ ) entes y mu..., mu agradables y mu... Que no..., no hay ninguna..., que siempre en algunos sitios siempre va alguien que..., que se va espachando; esa va... Toas parecen bien y esa es la que va estropeando [RISAS] [Rndo: lo demás]. Son ustedes mu graciosas y mu... eso, mu apañ (á = adas ) y mu agradables y to. (Álora, Málaga).

61. pero está muy solitaria. iOy!, [OTRAS-EM] muy solitaria, esto es muy aburrío, esto es muy aburrío, esto es esesperante vaya, esesperante. (La Atalaya (Villanueva de Algaidas), Málaga).

62. Yo he ido muchos años... allí a un hoté que había mu arreglao, y yo me iba el veintiocho de septiembre, pa pasá allí la feria, y en esta temporada estaba más barato ya, y había de fruta y... el de al lao, de to, y yo decía: “iAy, ay qué pasas más buenas!”. Cogía dos o tres pa matá el gusanillo, pero que no. [R-Vcs] No te rías, tú te ríes muncho. (Cañete de las Torres, Córdoba).

63. y entonces me gustaba jugá con las niñas gratuitas. Yo he tenido muchas amigas de la otra clase porque algunas niñas de mi clase eran muy estiradas y no querían na. Yo no, yo no, yo nunca, nunca me, me, me he sentío más que a otras, ni na (Antequera, Málaga).

64. Pues era mu... mu cu-, verás, muy distinguido él. [HS:E1 ¿Sí?] Mu corpulento, sí. Sí, sí. (Cañete de las Torres, Córdoba).

65. Él... Estábamos enfa-..., nos enfadábamos, ¿eh? No te creas que no nos enfadábamos pero bien. Pero él era mu suyo, mu cerr ( ao = ado ). Yo charlaba más, pero, [A-PIn: verás]... Y yo decía: "Pues, hasta que tú no hables, no hablo yo". (Alanís, Sevilla). 
66. Teníamos a to a, a to el, el ala aquella del hospital la teníamos a toa [P-Enf: pervertía] iMe cago en la leche! No dejábamos pará ni a enfermeras ni a [A-Inn]. Yo pa eso he sío muy joío siempre pero le digo de que ya, una noche [A-Inn] [TOS] si... el otro día se operaba uno, que estaba ahí en la otra habitación, porque yo, a mí me tenían una habitación pa mí solo y pa mi mujé . Digo: «Mañana quiero el alta que me voy pa casa». «Tu no te vas pa casa». «iCómo que no me voy pa casa! (Cortelazor, Huelva).

67. Bueno, ¿y allí qué pasa? Aquí... el... por el, el, si el, [R-Vhc] el pueblo nos pone a nosotros, pa que defendamos sus cosas y ahora, ¿tú qué quieres?, ¿qué vienes a engañá al pueblo a quearte con dinero, a enriquecerte...? ¿ ¿y ahora?, ¿qué te lleva? Do- I con dos años en la carce... y ya está?, ¿y con eso pagas lo suficiente? [HS:E2 [Asent].] Hay que tomá otras medidas y por eso lo, los ciudadanos realmente al | le tenemos tan poca fe a... los políticos porque son | los vemos muy corruptos, (Chucena, Huelva).

68. ¿Que si muerden los cerdos? Las botas de agua en uno [A-Inn], unas botas de agua hasta aquí, [G-Mst] íbamos protegíos pa que no te cayera agua caliente. [R-Ind] Meter el diente arriba y rajar es lo mismo que si [A-PIn: le metes] entera. Son mu expertos / lo cerdo son mu expertos en el... Tienes tú que pillá pillar la vez, como dejes que te pille la vez, ya eres cadáver. ¿Me comprendes lo que te quiero decí? (Terque, Almería).

Quiero, por otro lado, llamar la atención sobre algunos casos en los que teóricamente no podría darse la modificación en el grado al tener ya el participio o adjetivo un valor elativo o al encontrarnos ante adjetivos relacionales. Así, adjetivos como helá, correcto o perfecto presentan el punto más alto de la escala y, sin embargo, los hablantes en estos casos no tienen problema en graduarlos; se trata, de todas formas, de casos esporádicos justificables quizás por la oralidad:

69. Allí había una pila, un estanque | una... | de agua tenía un bujero , lo abrías, lo cerrabas y allí..., allí lavabas pero con agua fría. Te ponías unos guantes, porque estaba mu helá y allí lavabas. Sí y aluego pues la tendías ahí en los huertos co- | había una finca pues la tendías allí en los huertos. (Los Tablones (Órgiva), Granada).

70. I1: Pero mira sí y sí y tos sí y sí... yo iba, les llevaba la corriente pero yo... mentar la ese ¿pa qué? Si aluego tengo | me voy a mi pueblo y tengo que hablá... como habla la gente aquí, en Órgiva. Aquí hay gente muy educá, hablan muy bien, mu correcto, mu... claro... (Los Tablones (Órgiva), Granada). ${ }^{10}$

71. I1: No..., no pasaba nada, hombre. Si alguien no tenía... para pagá, el médico ha sido... siempre... Los médicos, [OTRAS-EM] yo para mí son las mejores personas del mundo. El médico [Rndo: tanto antes como ahora,] el médico es... yo creo que son los que verdader- I los únicos

\footnotetext{
${ }^{10}$ Obsérvese que en estos casos estamos realmente ante adverbios, no ante adjetivos.
} 
que verdaderamente vale la pena... que estén en la vida porque [R-Vhc] son... gente muy abnegados, gente muy preparada, muy preparada, gente muy perfecta, tanto enfermeras como..., como médicos. Los médicos, los médicos son muy altruistas, son gente muy... (Aguilar de la Frontera, Córdoba).

También localizamos, como he señalado, adjetivos relacionales modificados en su grado, lo que según las distintas gramáticas sería imposible. Demonte (1999: 137138), por ejemplo, al presentar los rasgos que definen a estos adjetivos, menciona, entre otros, la obligación de posponerse al nombre al que modifican (*mecánico taller); la imposibilidad de ser usados predicativamente (*la crítica es musical); la imposibilidad de presentar antónimos (*amecánico); la imposibilidad de coordinación con adjetivos valorativos ( ${ }^{*}$ taller mecánico y viejo); o -lo que ahora nos interesa- el no poder entrar en comparaciones o ser modificados por adverbios de grado (*clínica muy dental). Sin embargo, en el COSER, se observan algunos ejemplos en los que esta gradación está presente:

72. Y le va por aquí, por aquí y le va aquí a una tripa y le... dijo... el doctó que l'operó que no hay operaciones de estas casi ninguna, como la [NP], [HS:E2 [A-Inn]] esa operación, pero él no mueve la lengua ni hace... [G-Mst] Así está. Le hicieron una operación muy divina... (Los Tablones (Órgiva), Granada).

73. Mu divina, la operación. (Los Tablones (Órgiva), Granada).

74. 11: Pues era dale una fanega de trigo al año y iba to las veces que necesitaras a tu casa. [RISAS], <asentđ< span="'">]</asentđ<> [Asent]. [HS:I3: Pos ahora es igual.] Esa era la iguala. Le dábamos... Era..., el médico era familia de mi marido, pero, bueno, lo mismo era que fuera familia que no fuera. Él iba, le daba una fanega de trigo t ( o = odos ) los veranos y, si tenía que visitarte, y era $m u$ visit $(a o=a d o) ~ r$, si tenía que visitarte cincuenta veces o cien veces o, o t ( o = odos ) los días con su maletín de casa en casa, visitando sus enfermos. <asentđ< span="" > ]</asentđ<> [Asent]. (Puebla de Don Fadrique, Granada).

75. Pos a mí, yo no he sío muy carnicero la verdá porque yo tengo la chacinería que tiene mi nieta y como de higos a brevas la carne, no soy mu carnicero pero vamos, si se tercia, cualquiera me, me gusta, estando bien aliñá, cualquiera. (Constantina, Sevilla). ${ }^{11}$

76. En el verano lavábamos [A-Inn] mente pero ya cuando iba el agua del canal, iojú! Teníamos un pozo tambié... retirao de mi casa, que también ibamos... | pero ese pozo era pa lavá mu malo, mu malo | era mu clara, mu clara, pa bebé, pero era mu mala pa..., era mu salobre pa..., pa, pa

\footnotetext{
${ }^{11}$ Aquí, obviamente, el adjetivo adquiere un valor diferente al habitual y pierde su carácter relacional.
} 
lavá. Y pa bebé no, fíjate tú, se bebía el agua y ahora no se quiere agua ni de los grifos, de botella. Hola. (Torrecera (Jerez de la Frontera), Cádiz).

Se observa, pues, cómo hay adjetivos que parecen escapar a las normas gramaticales en ocasiones, como ha venido ocurriendo a lo largo de la historia del español, tal y como puede comprobarse en ejemplos como los siguientes, en los que el adjetivo relacional aparecía graduado: "E cada vno dellos es muy grande e muy malo e muy mortal para el cuerpo e para el alma" (1293, Anónimo, Castigos e documentos para bien vivir); "a mas baxa parte de la nuve, do la materia es mas terrenal. Estas son sus colores mas principales" (1494, Fray Vicente de Burgos, Traducción de El Libro de Propietatibus Rerum); "que la gente (que es carnalíssima) vendrá luego a caer en la red: pero han de proceder con cautela" (1612-1625, Fray Juan Márquez, El gobernador cristiano).

Por otra parte, entre los adjetivos que aparecen modificados por muy, observamos casos de doble intensificación con muy e ísimo, ${ }^{12}$ pese a lo afirmado por distintos gramáticos, Así, Alcina \& Blecua (1975: 580-581), desde una perspectiva prescriptiva decían:

Resulta redundante y los gramáticos rechazan como grave incorrección la agrupación del superlativo en -ísimo con el refuerzo muy (muy altísimo). Se suele emplear en la lengua vulgar con intención hiperbólica y encarecedora.

Podría resultar, efectivamente, redundante, pero se usa porque, cuando se produce en alguna medida un desgaste esencial del valor superlativo, el hablante -que no es necesariamente un hablante "vulgar"- intenta recuperarlo mediante otros recursos.

En el mismo sentido Bosque (1999: 228) también se pronuncia al respecto:

\footnotetext{
${ }^{12}$ Cuando hablo de doble gradación no me refiero, por supuesto, a los casos de más mayor referidos a la edad, que son muy abundantes en el corpus manejado y de uso común en español actual. En el COSER es posible localizar también casos en los que muy modifica a un adjetivo con un sufijo aumentativo; no es lo más habitual, pero no es extraña en español actual una construcción como la siguiente: "Me tienes ya harta, todavía me voy a í a Juan y Medio. [RISAS]. Juan y Medio es uno mu grandón, que es el presentadó" (Cañete de las Torres, Córdoba).
} 
Los adjetivos elativos no admiten modificadores de grado porque contienen léxicamente la información correspondiente a la gradación extrema: enorme, exhausto, extraordinario. (...) Aun así, a veces aparecen con ellos en el español clásico y en el coloquial actual, lo que sugiere que su fuerza intensificativa está atenuada en estos estados de lengua.

\section{Obsérvense algunos de los ejemplos extraídos del COSER:}

77. Y hay mucho trabajo ahí en ese pueblo y hay otro más pa allá que le dicen... Cabra. Igualito, es mu grandísimo también. Y otro aquí más pa acá que le dicen Rute; otro que hay, le dicen | ya eso hacia la parte de Córdoba, eso hacia la parte de Córdoba. Pero Málaga tiene eso que te he dicho. Además, Andalucía la veis usted por la tele en el tiempo, que es muy grande. Andalucía es muy grande, tiene ocho provincias, así que mira. [RISAS] [SLNC] Y ya perdonáis si he hablao algo malamente. (La Atalaya (Villanueva de Algaidas), Málaga).

78. Cómo no vayas con una persona que sepa, llegas y ves las calderas abajo pero luego el charco de arriba que | lo que es el charco malo no lo ves, no lo ves porque no se ve de ningún lao es to un risco mu altísimo, un risco por los laos y, y, y está na más que el gujero aquel allí. Es un charco que no tiene fondo y es e-, enorme. (Cortelazor, Huelva).

79. Sí, esto... pero eran unos trenes muy malísimos. Esos di- I echaban en ir a, a Madrid, echaban dos días o tres, yo qué sé. (Ventorros de San José (Loja), Granada).

80. I1: ¡Buh! Allí, en el cortijo tenemos dos o tres, por delante del cortijo, que tendrán, yo qué sé, quinientos años, yo qué sé, unos troncones, como eso, y... muy grandísimo. (Ventorros de San José (Loja), Granada).

81. En las orzas, sí. Y el pan se hacía un amasío y tenía..., había una orza en mi casa que era mu grande, era una..., una orza mu grandísima, esa orza de..., como hay hoy hecho de barro y eso, pero es una orza mu grande. (Álora, Málaga).

82. O sea es una iglesia mu grandísima. Es de las antiguas, antiguas; hace como una cruz. Tiene arriba allí, y ara tiene dos huecos así, y larga. (Jubrique, Málaga).

83. Además de la nuestra, dos o tres casas más en las eras teníamos, que habíamos heredao de..., de mi abuela a medias. Media casa, que era mu grandísima, como yo te he dicho, onde yo nací. (Alanís, Sevilla).

84. Pero bueno no, la feria, no es la feria del pueblo, es la feria de tos los pueblos que hay en... Málaga, un... como te digo a ti, un pabellón mu grandísimo y ahí ponen la... un... [HS:E1 Un puesto de cada pueblo.] un puestecito de cada pueblo y hay ciento un pueblo en Málaga. (La Atalaya (Villanueva de Algaidas), Málaga). 
La doble intensificación es una construcción que se documenta ya en el latín popular y que no es extraña en el español antiguo; sobre ella ya reflexionaban Pons (2012) o Wang (2013), quienes, en ningún momento la catalogan de vulgar. Véanse algunos ejemplos del español de siglos anteriores: "I vos, muy mucho querida seredes toda mi vida" (Coplas de Mossén Fernando); "Entre las otras palauras vna dixo fort excellent / et dixo de memoria" (1377-1396 Fernández de Heredia, Juan: Historia Eutropio); "la cual muncho [sic] dexamos arriba * dicho-, asaz iniquísimo" (1527-1561, Fray Bartolomé de las Casas: Historia de las Indias). Fernández Ramírez (1986: 62) mencionaba también lo que él llama construcciones pleonásticas como superiorísimo o exteriorísimo y cita, incluso, un ejemplo de Valle Inclán: "Es de muy malísimo tono restaurar amores viejos (Valle Inclán: Corte de Amor, II, 40)".

Esta doble intensificación, viva en la lengua coloquial de todas las regiones hispanohablantes, guarda relación con el desgaste de ciertas expresiones y con el hecho de que los hablantes no ven las formas muy e -ísimo como sinónimos absolutos, lo que permite su coexistencia en un mismo contexto. Véase un ejemplo como el siguiente en el que el hablante establece una gradación de forma que -ísimo queda en la posición más elevada de la escala de la superlación:

85. Mu cansao, cansadísimo del to. (Constantina, Sevilla). ${ }^{13}$

Por otro lado, en principio, el superlativo sería incompatible con un adverbio como relativamente, puesto que, en teoría, con el elativo sintáctico muy se está expresando un alto punto en la escala de la gradación sin establecer comparación con ningún otro elemento de la misma clase; es decir, no es posible relativizar el grado, pero obsérvese el siguiente ejemplo:

\footnotetext{
${ }^{13}$ Obsérvese también el siguiente ejemplo en el que para indicar el máximo grado el hablante precisa del sintagma preposicional "del todo": "Y los niños, pues están, porque verás, mi marío era, fue taxista, vaya fue taxista pero no era mu, muy torpe del to, vaya" (La Atalaya (Villanueva de Algaidas), Málaga). Es evidente que para esta informante muy no aporta información sobre el punto más alto de la escala de la gradación y por eso se ve obligada a buscar un refuerzo.
} 
86. Prácticamente de la viña ha pasao al olivar, por lo, por lo tanto hay muchísimos olivos jóvenes, [HS:E1 [Asent].] olivos de quince años, veinte años, que eso es relativamente muy joven en un olivo. Un olivo con cien años, u doscientos años no es viejo, [HS:E1 [Asent].] y esa es | es cultivo que había aquí antes. (Aguilar de la Frontera, Córdoba).

Estamos ante una oración que quedaría fuera de la norma, pero que al informante le sirve perfectamente para explicar lo que quiere decir: hay olivos muy jóvenes, olivos jóvenes y olivos que, incluso con doscientos años no pueden considerarse viejos; a los que él se refiere, los olivos de quince o veinte años, no se los puede catalogar en ningún punto de la escala y, por eso, recurre al adverbio.

Hasta aquí, hemos visto los distintos usos de muy en el área que nos ocupa; se trata de la forma superlativa más extendida $y$, en ocasiones, como se ha podido observar, se traspasan los límites de lo que podría considerarse normativo, en busca de una mayor expresividad o de una mayor precisión.

\subsection{El uso de -ísimo en Andalucía}

En este apartado daré cuenta de la presencia del superlativo sintético en el andaluz actual. Igual que he hecho al estudiar muy, a la hora de contar el número de apariciones, excluyo del cómputo algunas construcciones como los usos de cuantificadores con -ísimo con valor adverbial y aquellos casos de superlativos sustantivados (el Santísimo). Una vez realizados estos filtros, el número de ejemplos asciende a 99, cifra notablemente inferior a los usos de muy, que superan los mil casos.

La distribución de ejemplos por provincias es la siguiente: Andalucía Occidental (Huelva: 12, Córdoba: 17, Sevilla: 11 y Cádiz: 20); Andalucía Oriental (Málaga: 23, Granada: 9; Jaén: 4 y Almería: 3). Parece, pues, que es una forma más utilizada en la zona occidental de Andalucía, lo que contrasta con los datos que presentaba Lara (2018) para la primera mitad del siglo XX, extraídos del ALPI, que le permitían concluir que el superlativo sintético estaba presente básicamente el oriente peninsular. 
Dialectologia 28 (2022), 175-203.

ISSN: 2013-2247

Por otro lado, quiero destacar que, a diferencia del uso de muy, el superlativo sintético prácticamente no aparece con participios excepto en el caso de cansadísimo Respecto a la variedad de adjetivos documentados, encontramos los siguientes:

\begin{tabular}{|l|l|l|l|l|}
\hline \multicolumn{1}{|c|}{ ADJETIVO } & \multicolumn{1}{|c|}{ PREDICADO } & ANTEPUESTO & \multicolumn{1}{c|}{ POSPUESTO } & \multicolumn{1}{c|}{ TOTAL } \\
\hline Buenísimo & 13 & & 5 & 18 \\
\hline Riquísimo & 10 & & 2 & 12 \\
\hline Guapísimo & 12 & & 3 & 12 \\
\hline Grandísimo & 3 & & 1 & 6 \\
\hline Malísimo & 2 & & 1 & 3 \\
\hline Altísimo & 2 & & & 3 \\
\hline Contentísimo & 2 & & & 2 \\
\hline Cansadísimo & 1 & & 1 & 1 \\
\hline Larguísimo & & & & 1 \\
\hline Durísimo & 1 & & 1 & 1 \\
\hline Viejísimo & 1 & & & 1 \\
\hline Monísimo & & & 1 & 1 \\
\hline Pequeñísimo & 1 & 26 & & 34 \\
\hline Muchísimo* & 7 & & 15 & 1 \\
\hline Cuantísimo* & 1 & 2 & 2 & 99 \\
\hline Tantísimo* & & 28 & & 1 \\
\hline TOTAL & 56 & & & \\
\hline
\end{tabular}

Tabla 1. Adjetivos con superlativo sintético

Obsérvese cómo hay un total de 16 adjetivos modificados por -ísimo, que contrastan con la gran variedad de adjetivos modificados por muy (224). ${ }^{14} \mathrm{En}$ un trabajo anterior analicé todos los usos de -ísimo en el COSER (Serradilla, en prensa) y la cifra total era de 46 adjetivos; así, se puede afirmar que se observa una menor variación en Andalucía.

Por otro lado, observamos que, si eliminamos los cuantificadores, que básicamente aparecen antepuestos, la anteposición no se da con ningún otro adjetivo. La posición predominante es aquella en la que el superlativo aparece como predicado y hay también algunos casos de posposición. En porcentajes (eliminados los cuantificadores) la posposición se da en un $22,58 \%$, mientras que aparece como

\footnotetext{
${ }^{14}$ Excepto los cuantificadores, todos los adjetivos que se construyen con la forma sintética también lo hacen con muy.
} 
predicado el $77,42 \%$ de los casos, cifras cercanas a las que encontrábamos también en el caso de los adjetivos modificados por muy.

Propongo algunos ejemplos de cada estructura y, en primer lugar, citaré algunos casos de uso predicativo:

87. Los nietos, los chicos, los chicos, tengo dos chicos muy, muy graciosos y muy bonitos y la otra ya, tengo una con ventitrés años, otra con diecinueve, otro con veinte que es guapísimo [RISAS] y otro con diecisiete que es vamos. Estaba el otro día con un traje y una corbata, vamos, estaba guapísimo y otra con catorce eso, con catorce años y otra con trece, eso, con doce y otra con s-, con un siete y medio y aluego tengo dos chicos, uno con tres años y otro con dos. Muy bonitos, eso es la ilusión de mi vida, eso es... vamos (La Atalaya (Villanueva de Algaidas), Málaga).

88. De, de | bueno, el colegio | mi suegro se venía contentísimo: "Mira las becas que le han dao a mi niño. Mira que al niñ- | al [NP] le han dao lo otro, mira». (Antequera, Málaga).

89. Bueno, ahora ya sí, ya sí, pero entonces en aquellos tiempos a lo mejor tampoco había tanto, ¿no? Yo no sé. Pero claro, Jerez se [A-PIn: compone] que [OTRAS-EM] tiene muchas bodegas, porque esas bodegas son viejísimas, y [R-Ind] como tenía bodegas y eso pos había muchos hombres colocaos (Torrecera (Jerez de la Frontera), Cádiz).

90. sí... el chaval es [A-PIn: altísimo] un tío con dos metros de alto, pero un, pero un señor pa mí un..., mu bien, fabuloso, adonde estén que..., que estén bien y juntos, pero eh... Sí... (La Calahorra, Granada).

91. Por el cuarenta, cuarenta y cinco, por ahí, fue eso. <asentđ< span="">]</asentđ<> [Asent]. Entonces eso fue durísimo de velo y vivilo. (Alanís, Sevilla).

A continuación, muestro algunos casos en los que el adjetivo se pospone al nombre al que complementa:

92. Más. Uf [OTRAS-EM]. Nos caían unos nevazos... [HS:E1 ¿Sí?] Me acuerdo un año que nos levantamos aquí y abrimos la puerta y habi-, y había otra por delante de nieve. [HS:E [RISA]] Unos nevazos grandísimos. (Bacares, Almería).

93. Pero ya después me metieron a otra casa, y eran por un sitio que dicen la plaza de san Antonio. Y trabajaba con dos señoras buenísimas, y era un piso, bueno, aquello era que pa qué. (Los Pascuales (La Puerta de Segura), Jaén).

94. Yo tenía dos niñas, digo tres con esta [NP] y el niño, y yo [R-Glp] toa la ropita de mi niño y mis niñas se la hacía yo: de punto inglés..., [R-Glp] de, iojú!, trajes monísimos que les hacía. Antes no se compraba tanto como ahora, todo, todo, hasta la ropa de abajo se hacía... (Torrecera (Jerez de la Frontera), Cádiz). 
95. Y van todas las espigas pa el mismo lao. Y los pinchaban los carreteros, con unas horcas con un rabo laguísimo y lo iban poniendo mu bie, mu bie, y cuando ya tenía carga suelta, echabas los cinchos, que había que tené raíles pa echá los cinchos por lo alto de aquellos (Cañete de las Torres, Córdoba).

Por último, propongo algunos casos en los que el cuantificador antecede al nombre:

96. Y ya no, ya pos aquí normalmente hay una... yo creo que... eso [OTRAS-EM] una... hacienda y además las [A-PIn: les | antes] las que nosotros les llamamos haciendas, ¿no?, antes tenía muchísimos trabajadores debido a lo mismo que te he dicho antes, ¿no?, porque el producto era mu caro. (Chucena, Huelva).

97. Y claro no se vende, se ha abaratao mucho entonces la viña que había, había muchísimas viñas aquí en..., en Aguilar, Montilla, esta es la zona de Montilla, Moriles digamos, es el consejo reguladó, (Aguilar de la Frontera, Córdoba).

98. Eso lo pasarían muy mal, ieh!, porque, tú me dices a mí, tantísima gente pa tené tú que hacé las cositas ahí en el patio y en un corrá mu viejo que había [HS:E2: Ya.] pa hacé las cosas tú. (Alanís, Sevilla).

Hemos visto cómo el empleo de -ísimo es claramente menor que el de muy y a ello contribuyen las restricciones de uso que presenta. Wang (2013), a lo largo de su trabajo, va recogiendo algunas de estas restricciones apuntadas por distintos gramáticos; así, señala cómo ísimo rechaza los adjetivos cultos o de origen griego: *sagacísimo/sumamente sagaz, *demagogísimo/muy demagogo, tal y como indican Sánchez López (2006: 30) y Gómez Torrego (2000: 54), quienes también aluden a la imposibilidad de -ísimo para combinarse con adjetivos terminados en -ío (sombrío, baldío, tardío), salvo pío; y con los que terminan en -io (necio, propio, lacio), excepto sucio, limpio y amplio, o aquellos que terminan en -eo (aéreo, idóneo, etéreo), -uo (vacuo, ingenuo, inicuo, asiduo) y sus femeninos, (salvo antiguo), y los adjetivos esdrújulos terminados en -ico (salvo simpático y práctico).

Tampoco, salvo excepciones como interesante, importante, amante, brillante y pedante, o frecuente, valiente y caliente, los adjetivos terminados en -ante o -(i)ente admiten el uso de -ísimo (Sánchez López 2006: 30). Esto no quita para que, como señala Wang (2013), en otras épocas del idioma -siglos XVIII y XIX- se documenten 
casos como los siguientes: ignorantísima, vigilantísimo, extravagantísima, ardentísima, pestilentísima, potentísima, prudentísima, diligentísima, prudentísimo, diligentísima, elocuentísimo, eminentísimo, sapientísimo o sangrientísima.

Entre las restricciones, como señala Sánchez López (2006), está también el rechazo a -ísimo de los adjetivos situacionales, mientras que admiten la gradación con muy: muy próximo/*proximísimo. Wang (2013: 134) alude también a cómo los sufijos adjetivales más frecuentes en la formación de adjetivos de relación (-ivo, -ero, -ista, ario) son compatibles con cuantificadores sintácticos, pero en su mayor parte rechazan -ísimo, aunque ella documenta festivísimas aperturas en la obra de Isla (1758). EI hecho de que, en ocasiones, se encuentre documentación que anula alguna de las restricciones propuestas lleva a Wang (2013: 135) a afirmar que estas se van haciendo más férreas a lo largo de la historia de la lengua, de manera que "lo que en siglos anteriores era posible, en la época actual ha pasado a ser considerado agramatical".

En la documentación del COSER que se ha analizado en este estudio se hace evidente que estas restricciones se cumplen; en todo caso, los datos permiten afirmar que el superlativo en -ísimo, aun con más restricciones y menor frecuencia de uso que muy, está claramente integrado en el habla diaria de los hablantes andaluces.

\section{Reflexiones finales}

En este estudio se ha hecho una revisión del uso de muy e -ísimo a lo largo de la historia del español y se ha mostrado cómo los hablantes andaluces usan estas dos fórmulas elativas: la analítica con muy y la sintética con -ísimo. La primera de ellas es la que predomina con claridad, pues hay más de mil casos, mientras que los ejemplos de la segunda no llegan a la centena.

Además, se ha podido comprobar, gracias a los datos, que, pese a que no es la forma predominante, -isimo ha sufrido un importante avance respecto a épocas anteriores; así, frente a los datos del ALPI, que solo localizaban esta fórmula en el área oriental, en la actualidad observamos que se usa en todas las provincias andaluzas. 
Por otro lado, en este trabajo se ha aportado documentación que permite observar que las construcciones analizadas funcionan básicamente como predicados (70,2 \% en el caso de muy y 77,42 \% en el caso de -ísimo). La posposición del adjetivo al nombre modificado en su grado es también frecuente $(26,03 \%$ muy y $22,58 \%$-ísimo), mientras que la anteposición es prácticamente inexistente: solo un 3,77 \% en el caso de muy y un $0 \%$ en el de -ísimo. Se trata de unos datos explicables por el hecho de que los hablantes consultados muestran un nivel sociolingüístico bajo y en este registro la anteposición del adjetivo no es habitual; asimismo, tenemos que tener en cuenta que estamos ante textos de carácter oral, lo que determina su sintaxis.

En este estudio también se han tenido en cuenta las restricciones de uso de cada una de estas fórmulas y se ha observado que, en algunos casos, se producen transgresiones a la norma en busca de una mayor expresividad o precisión.

Asimismo, se ha atendido en este artículo a la variedad de adjetivos documentados con fórmulas elativas y se ha podido observar cómo hay hasta un total de 224 adjetivos modificados por muy, mientras que solo 16 aparecen con el superlativo sintético. Aunque -isimo ha sufrido un importante avance en los siglos XX y XXI, todavía conserva, aunque en mucha menor medida que en el español clásico, ese resquicio de valor culto que lo hace más infrecuente en el habla de los informantes de áreas rurales que componen el corpus objeto de estudio.

Un trabajo de estas características permite dar cuenta del uso de una pequeña parcela de la gramática del español hablado en Andalucía, al tiempo que supone un acercamiento al habla de un sector de la población que, a menudo, queda excluido de las investigaciones en torno a la lengua actual.

\section{Referencias}

AlCinA FranCH, J. \& J. M. BleCUa (1975) Gramática española, Barcelona: Ariel.

BOSQUE, Ignacio (1999) “El sintagma adjetival. Modificadores y complementos del adjetivo. Adjetivo y participio", in Ignacio Bosque/Violeta Demonte (dirs.), Gramática descriptiva de la lengua española, Madrid: Espasa Calpe, 217-310. 
BOSQUE, Ignacio $\left(2015^{2}\right)$ Las categorías gramaticales, Madrid: Síntesis.

ADMYTE (Archivo Digital de Manuscritos y Textos Españoles): versión en CD [existe nueva versión en red: http://www.admyte.com/presentacion.htm].

Company Company, Concepción. (ed.) (2006) Sintaxis histórica de la lengua española, Vol. I. La frase verbal, México: FCE-UNAM.

CORDE: ReAl Academia Española: Banco de datos (CORDE) [en línea]. Corpus diacrónico del español. http://www.rae.es.

DEMONTE, Violeta (1999) "El adjetivo: clases y usos. La posición del adjetivo en el sintagma nominal", in Ignacio Bosque/Violeta Demonte (dirs.), Gramática descriptiva de la lengua española, Madrid: Espasa Calpe, 129-215.

FERNÁNDEZ-ORdóÑEZ, Inés (dir.) (2005-2020) Corpus Oral y Sonoro del Español Rural. (www.uam.es/coser) [consultado en noviembre de 2019-enero de 2020].

FERNÁNDEZ RAMíREZ, Salvador (1986) Gramática española, vol. 3.1. El nombre, (vol. preparado por José Polo), Madrid: Arco/ Libros.

García Mouton, Pilar (coord.), Inés Fernández-Ordóñez, David Heap, Maria Pilar Perea, João Saramago, Xulio SouSA (2016) ALPI-CSIC [www.alpi.csic.es], edición digital de Navarro Tomás, Tomás (dir.), Atlas Lingüístico de la Península Ibérica, Madrid: CSIC.

GómEZ TORREGO, Leonardo (2000) Gramática didáctica del español, Madrid: SM.

LARA, Víctor (2018) "El superlativo absoluto en el español peninsular del siglo XX", Rilce, 34.1, 225-239.

Pato Maldonado, Enrique \& Xulio Viejo Fernández (2016) “Mucho bien y mucho guapa: mu (n) cho como cuantificador 'pleno' de adjetivos y adverbios en castellano y en asturiano", Bulletin of Spanish Studies, 92, 1-23.

Pons RodríGUez, Lola (2012) "La doble graduación muy -ísimo", in Enrique Pato (ed.), Estudios de Filología y Lingüística españolas. Nuevas voces en la disciplina, Berna: Peter Lang, 135-166

Real ACAdemia Española Banco de datos (CORDE) [en línea]. Corpus diacrónico del español $<$ http://www.rae.es>.

SÁNCHEZ LÓPEZ, Cristina (2006) El grado de adjetivos y adverbios, Madrid: Arco Libros.

SerRADILla CAStaño, Ana (2005) "Evolución de la expresión del grado superlativo absoluto en el adjetivo: las perífrasis sustitutivas del superlativo sintético en español antiguo", Cauce: Revista de Filología y su Didáctica, 28, 357-386. 
SerRadilla CAStaño, Ana (2008) "Una diferencia sociolingüística en el uso de las fórmulas superlativas en español medieval", in J. L. Blas Arroyo et al. (eds.), Discurso y sociedad II. Nuevas contribuciones al estudio de la lengua en un contexto social, Castellón: Universidad, 597-609.

SerRadilla CAStaÑo, Ana (2016) "Sobre la expresión de la superlación en el español contemporáneo: la convivencia de nuevas y viejas fórmulas", Revista de la Sociedad Española de Lingüística, 46, 1, 13-44.

Serradilla CAStaÑo, Ana (2017) "Tope (de) + adjetivo: un elemento innovador en el paradigma de la superlación en español actual", Círculo de Lingüística aplicada a la comunicación, 70, 272-297.

SeRRAdilla CAStAÑo, Ana (2018) “Los mecanismos de superlación en la General Estoria (primera parte): la consolidación de un modelo romance", Atalaya, 17, 1-18.

<https://journals.openedition.org/atalaya/2566?lang=es>

Serradilla CAStaño, Ana (en prensa) "El uso del superlativo sintético en el español rural", in Homenaje..., Buenos Aires: Universidad de La Plata.

WANG, Chaofang (2013) Las fórmulas superlativas en el español de los siglos XVIII y XIX, Tesis Doctoral. Madrid: Universidad Autónoma de Madrid. <https://repositorio.uam.es/bitstream/handle/10486/660732/wang_chao_fang.pdf?seq uence $=>$

ZIELIŃSKI, Andrzej (2013) “Evolución semántico-sintáctica del sufijo superlativo -ísimo en castellano", Romanica Cracoviensia, 13, 105-115. 